\title{
Bone regenerative effect of recombinant human bone morphogenetic protein-2 after cyst enucleation
}

\author{
Doo Yeon Hwang ${ }^{\dagger}$, Sung Woon $\mathrm{On}^{\dagger}$ and Seung $\|$ Song ${ }^{*}$
}

\begin{abstract}
Background: The aim of this study is to quantitatively evaluate the effect of rhBMP-2 for repair of bone defects after cyst enucleation using the osteogenesis index (OI).

Methods: Under general anesthesia, 10 patients (12 lesions) underwent oral or maxillofacial surgery for cyst enucleation. Postoperatively, 12 lesions were divided into two groups: group A (six lesions) was treated with absorbable collagen sponge (ACS) in combination with rhBMP-2, and group B (six lesions) was treated with ACS alone. After 3 months, cone-beam computed tomographic scans were obtained to measure changes in the volume of the lesions. We then calculated the Ol of each group at two different Hounsfield units to determine any statistically significant difference between these two groups (Mann-Whitney $U$ test).

Results: As tested at the level of new bone, the mean Ol was $72.37 \%$ in group A and $55.08 \%$ in group B - a statistically significant difference $(p=0.041)$. As tested at the level of mature bone, the mean Ol was $27.47 \%$ in group A and $18.88 \%$ in group B, but the difference was not statistically significant ( $p=0.394)$.

Conclusions: The application of rhBMP-2 after maxillofacial cyst enucleation accelerated new bone formation in the bone defects. Thus, the use of rhBMP-2 in combination with ACS may be considered an alternative to conventional bone grafting in some patients with postoperative bone defects.
\end{abstract}

Keywords: rhBMP-2, Bone regeneration, Bone defect

\section{Background}

Bone defects in the oral and maxillofacial region have many different causes, such as infection, trauma, lesions, or invasive surgery. Because such defects require faster healing and complete reconstruction to achieve functional and esthetic recovery, numerous studies and relentless efforts have been undertaken to fulfill these requirements. As a result, a variety of bone graft materials and osteogenic factors have been examined but have not led to ideal alternatives or substitutes, so relevant studies are ongoing.

Bone morphogenic proteins (BMPs) were discovered in 1965 by Urist [1], revealing their ability to differentiate undifferentiated osteogenic progenitor cells. Unlike

\footnotetext{
* Correspondence: seungilsong@daum.net

${ }^{\dagger}$ Equal contributors

Department of Oral and Maxillofacial Surgery, Institute of Oral Health

Science, Ajou University School of Medicine, 164, World Cup-ro,

Yeongtong-gu, Suwon-si, Gyeonggi-do 16499, Republic of Korea
}

conventional bone graft materials, which are only osteoconductive, BMPs are osteoinductive and therefore represent an optimal alternative to bone grafting for reconstruction of the oral and maxillofacial region [2]. Various applications of rhBMP-2 have been explored since it was approved in 2007 as a substitute for autografts in maxillary sinus augmentation and alveolar ridge defects around an extraction socket. Previous studies have demonstrated that rhBMP-2 is effective for cleft lip and palate, alveolar bone augmentation, sinus augmentation, osteonecrosis of the jaw, and reconstruction of the oral and maxillofacial region [3-5].

Intrabony cysts are common lesions of the oral and maxillofacial region and often require surgical removal. In many cases, after removal of the cyst, bone grafting is performed using a particle-type bone graft material. Recently, however, because bone graft materials may become dispersed or may migrate depending on the size or 
location of the defect and the bony housing of the lesion [6], absorbable collagen sponge (ACS) with absorbed BMPs has occasionally been used instead [7].

Although many studies have already shown the bone regenerative effects of rhBMP-2, most of these were in vitro or animal studies in which rhBMP-2 was added to other bone graft materials, and some of the clinical reports involved non-quantitative methods. Our study was intended to analyze the bone regenerative effects of rhBMP-2 quantitatively based on cone-beam computed tomographic (CBCT) images of patients treated with and without rhBMP-2.

\section{Methods}

\section{Patients}

We evaluated 38 patients who visited the Department of Oral and Maxillofacial Surgery at Ajou University Hospital in South Korea from January 1, 2014, through March 31, 2015 , and who underwent cyst enucleation under general anesthesia. For our study, the following selection criteria were applied:

\section{Inclusion criteria}

- Both preoperative and 3-month postoperative CBCT images were available.

- ACS alone or rhBMP-2 plus ACS was used for bone defect repair.

\section{Exclusion criteria}

- Recipients of bone grafts (allogenic or xenogenic bone material).

- Patients with diseases related to bone metabolism (e.g., osteoporosis).

Based on these criteria, we selected 10 patients for study, two of whom each had one additional, independent lesion, for a total of 12 lesions. Human CBCT data were used in this study but patient consent was not necessary. This study was reviewed and approved by the institutional review board of Ajou University Hospital (AJIRB-MED-MDB-15-203).

\section{Methods \\ Study design}

Two operators performed cyst enucleation for 12 lesions. After a retrospective chart review, we divided the 12 cases into two groups of six lesions each: group A was treated with rhBMP-2 plus ACS, and group B was treated with ACS alone. Preoperative and 3-month postoperative lesion volumes were measured on CBCT images, and the osteogenesis index was calculated in each case, after which, a statistical analysis was performed.

\section{Surgical procedure}

After cyst enucleation under general anesthesia, ACS with absorbed rhBMP-2 was applied on the bone defects in group A and primary closure was completed. In group B, ACS alone was applied after cyst enucleation, with subsequent primary closure (Fig. 1). Up to five units of ACS was used and up to $1.0 \mathrm{mg}$ of rhBMP-2 $(1 \mathrm{mg} / \mathrm{mL})$ was used, depending on the size of the lesion. The rhBMP-2 used in this study was NOVOSIS (Daewoong Pharmaceutical Company, Seoul, South Korea), and the ACS was either Ateloplug (Bioland, Cheonan, South Korea) or Rapiderm Plug (Dalim Tissen, Seoul, South Korea).

\section{Lesion volume measurements}

Each case was analyzed using Simplant software (Materialise Dental, Leuven, Belgium). From among the user's tools, we selected only those pixels (Fig. 2) within the preset range of Hounsfield units (minimum $=-1024 \mathrm{HU}$; maximum $=200$ or $600 \mathrm{HU}$ ) for all the coronal or axial images believed to include lesions. The selected pixels were then remodeled into three-dimensional images, and the volumes were calculated. Hounsfield units ranged from -1024 (minimum) to 200 (new bone level)

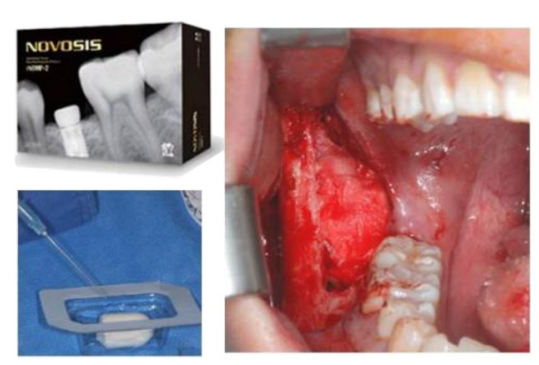

Group A

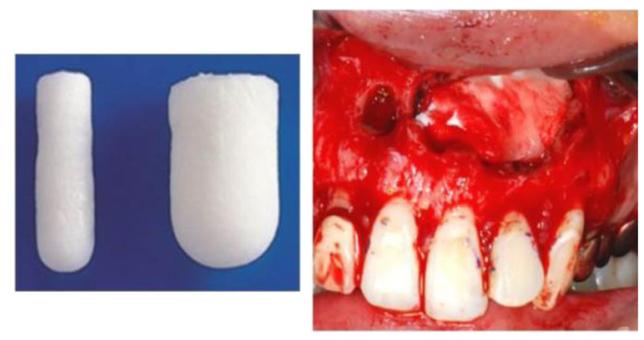

Group B

Fig. 1 Surgical procedures for group A and group B. In group A, ACS with absorbed rhBMP-2 was applied to the bone defects. In group B, ACS alone was applied to the bone defects 

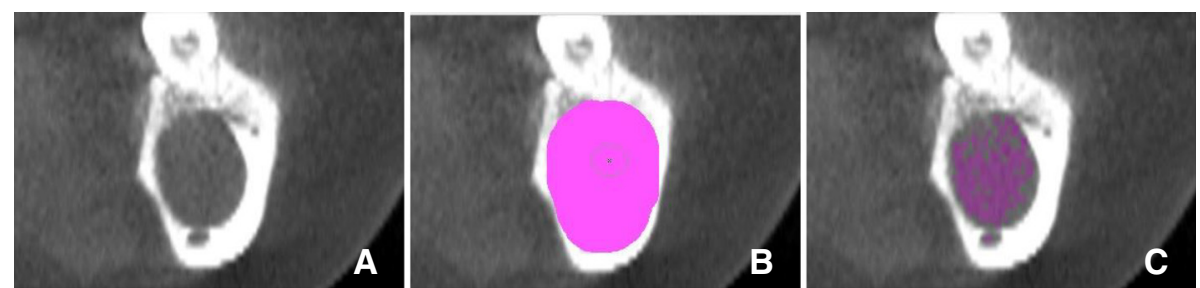

Fig. 2 Selection of pixels within the range of Hounsfield units desired (selection process). a Original CBCT image. b Drawing of lesional area. c Selected pixels

or 600 (mature bone level) (maximum), in reference to the studies performed by Norton and Gamble [8], Shapurian et al. [9], and Tajima et al. [10] (Fig. 3). Specifically, we defined two ranges: range 1 included $-1024<$ $\mathrm{HU}<200$ and range 2 included $-1024<\mathrm{HU}<600$. For range 1, pixels with volumes of $<200 \mathrm{HU}$ were regarded as a lesion; for range 2, pixels with volumes of $<600 \mathrm{HU}$ were regarded as a lesion.

To minimize any possible visual errors during measurement, the patient's head position on CBCT images was repositioned prior to volume measurement by using the line connecting the bilateral orbitales on the coronal plane, the line connecting the anterior nasal spine (ANS) and the cervical vertebra on the horizontal plane, and the line connecting the ANS to the posterior nasal spine (PNS) on the sagittal plane. To ensure accuracy, volume measurements were done twice in each case, and the mean results were used in this study.

\section{Calculation of $\mathrm{OI}$}

Preoperative lesion volume was defined as $V_{0}$ and postoperative lesion volume as $V_{\mathrm{h}}(\mathrm{HU}=200$ or 600) (Fig. 4). The OI was calculated as $\left(V_{0}-V_{\mathrm{h}}\right) / V_{0}(\%)$.

\section{Assessment and statistical analysis}

Using OI, we compared osteogenesis in groups A and B, and differences with a $p$ value of $<0.05$ were considered statistically significant. The Mann-Whitney $U$ test and SPSS version 22.0 (IBM, NY, USA) were employed as the statistical technique and software program, respectively.

\section{Results}

The patients ranged in age from 16 to 50 years (mean age $=36.25$ ), and the ratio of male-to-female patients was 9:1. Of the 12 lesions, nine were located in the mandible and the other three in the maxilla. Histological findings for the individual lesions indicated that there were nine dentigerous cysts, two periapical cysts, and one keratocystic odontogenic tumor (KCOT) (Table 1). All the lesions healed with no remarkable complications.

The measurements of preoperative lesion volume $\left(V_{0}\right)$ ranged from 1.24 to $14.82 \mathrm{~cm}^{3}$, with a mean of $5.25 \mathrm{~cm}^{3}$. The OI measurements at the level of new bone ranged from 29.88 to $88.21 \%$, with a mean of $63.72 \%$, and at the level of mature bone from 5.12 to $55.33 \%$, with a mean of $23.17 \%$. When postoperative lesion volume was measured, increases in the number of Hounsfield units

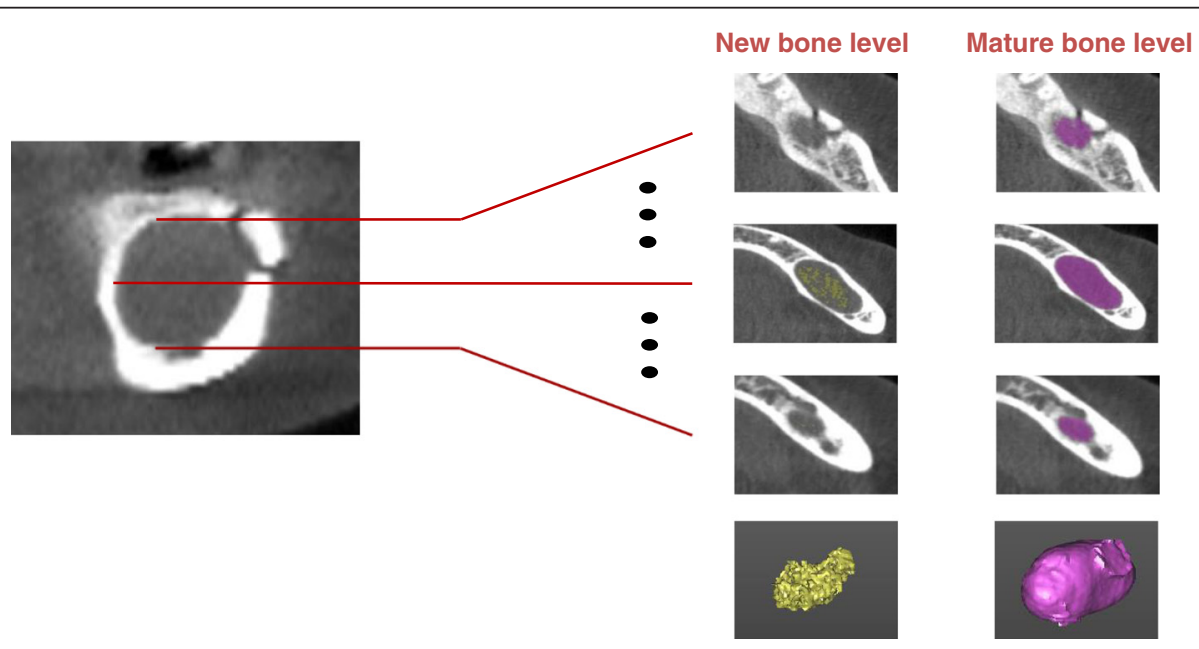

Fig. 3 Remodeling to a three-dimensional model. Selection of pixels regarded as lesions at the new bone level and the mature bone level for all computed tomographic images 

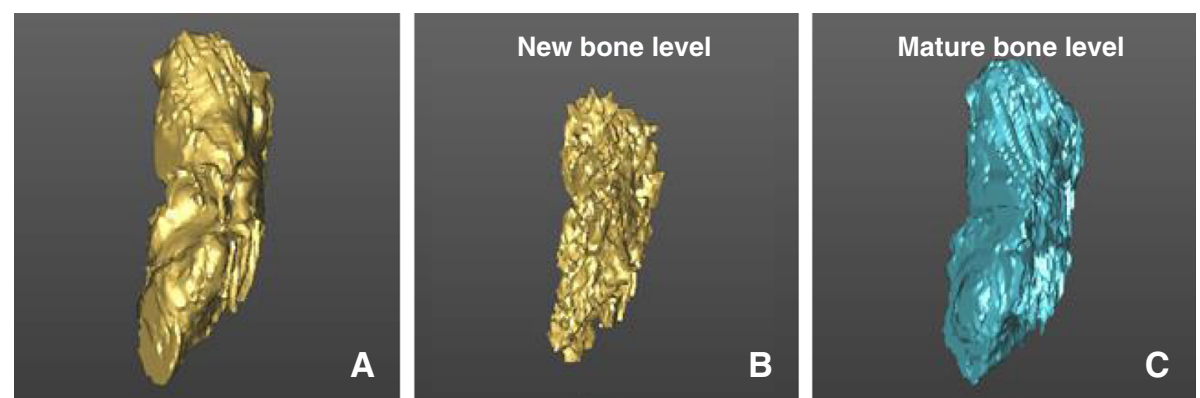

Fig. 4 Initial lesion and reduced lesion after 3 months. a Preoperative lesion. b Postoperative lesion at new bone level. c Postoperative lesion at mature bone level

were seen throughout the lesions, especially around the margins.

When tested at the new bone level, the mean OI was $72.37 \%$ for group A and $55.08 \%$ for group B-a statistically significant difference $(p=0.041)$. However, when tested at the mature bone level, the mean OI was $27.47 \%$ for group A and $18.88 \%$ for group B, a difference that did not reach statistical significance $(p=0.394)$ (Table 2 and Fig. 5).

\section{Discussion}

Human bone regenerates through patterns of maturation similar to those of bone growth in response to bone defects of any cause. Stable bone healing is achieved when there is an adequate blood supply and immobilization at the site of the defect. For the first 4 weeks, angiogenic and osteogenic cells originate from the surrounding bone walls and periosteum, while woven bone forms around the defect. These processes are governed by various cytokines and growth factors [11-15].

Ettl et al. suggested that although primary closure after cyst enucleation can be accomplished without bone grafts, further research regarding growth factors, osteoblasts, stem cells, and other components is needed to understand this process more fully [16]. Bone defects up to $3 \mathrm{~cm}$ in diameter usually undergo complete ossification after 12 months, while larger bone defects may require a longer period of ossification (24 months or more) $[17,18]$. In spite of the obvious need for additional treatment to accelerate healing (e.g., bone grafting), such measures cannot always be taken when possible complications such as infection or migration are of concern. Recently, ACS with absorbed rhBMP-2 has been applied in such situations.

In his primate study, Boyne reported that rhBMP-2 alone was useful even without bone graft material for the reconstruction of facial bone defects after mandibular hemisection, implant, and cleft repair [19]. After reviewing the literature on alveolar ridge augmentation, maxillary sinus augmentation, and/or extraction socket preservation, Freitas et al. reported that ACS with absorbed rhBMP-2 appeared to function as an alternative to autografting in alveolar ridge or maxillary sinus augmentation [20]. Balaji reported the use of rib grafting and rhBMP-2 following removal of an aneurysmal bone cyst [2], and in 2014, Lee et al. also reported the use of rhBMP-2 and $\beta-\mathrm{TCP} / \mathrm{HA}$ (tricalcium phosphate/ hydroxyapatite) in five patients with cysts [21].

Unfortunately, however, there have been some limitations to the use of rhBMP-2 despite the successful outcomes described above. These include the shorter half-life of BMP-2 and its rapid elimination at the application site, which requires a high dose of BMP-2 and thus expensive medical costs, overgrowth of bone, and unwanted side effects, including swelling due to immune reactions $[7,22,23]$. According to a recent report, excessively high doses of BMP-2 may cause oral squamous cell carcinoma [24]. However, we did not observe complications in any of the patients treated at our hospital.

One can compensate for the abovementioned disadvantages of BMP by selecting an appropriate carrier. Currently available carriers include HA, TCP, DBM,

Table 1 Characteristics of the 12 lesions

\begin{tabular}{llllll}
\hline Group & Age (year) & Gender & Site & Diagnosis & $V_{0}\left(\mathrm{~cm}^{3}\right)$ \\
\hline & 16 & M & Mandible & DC & 14.82 \\
& 50 & F & Mandible & DC & 1.98 \\
A & 21 & M & Mandible & KCOT & 6.47 \\
(ACS + rhBMP-2) & 45 & M & Mandible & DC & 2.27 \\
& 41 & M & Mandible & DC & 3.14 \\
& 20 & M & Mandible & DC & 5.02 \\
& 51 & M & Mandible & DC & 2.30 \\
B & 48 & M & Maxilla & PC & 6.64 \\
(ACS alone) & 37 & M & Mandible & DC & 1.24 \\
& 37 & M & Mandible & DC & 2.67 \\
& 45 & M & Maxilla & DC & 2.95 \\
& 40 & M & Mandible & PC & 13.48 \\
\hline
\end{tabular}

$D C$ dentigerous cyst; $P C$ periapical cyst; KCOT keratocystic odontogenic tumor 
Table 2 Preoperative and 3-month postoperative mean volume ( \pm SD) and mean OI ( $\pm S D$ ) of lesion

\begin{tabular}{|c|c|c|c|c|c|}
\hline \multirow[t]{2}{*}{ Group } & \multirow[t]{2}{*}{$V_{0}$} & \multicolumn{2}{|l|}{ New bone } & \multicolumn{2}{|c|}{ Mature bone } \\
\hline & & $\overline{V_{200}\left(\mathrm{~cm}^{3}\right)}$ & OI (\%) & $\overline{V_{600}\left(\mathrm{~cm}^{3}\right)}$ & OI (\%) \\
\hline $\begin{array}{l}\mathrm{A} \\
(\mathrm{ACS}+\mathrm{rhBMP}-2)\end{array}$ & $5.62 \pm 4.82$ & $1.67 \pm 1.60$ & $72.37 \pm 14.39$ & $4.56 \pm 4.57$ & $27.47 \pm 17.09$ \\
\hline $\begin{array}{l}\text { B } \\
\text { (ACS alone) }\end{array}$ & $4.88 \pm 4.60$ & $1.79 \pm 1.14$ & $55.08 \pm 15.26$ & $3.81 \pm 3.21$ & $18.88 \pm 11.15$ \\
\hline
\end{tabular}

$V_{0}$ preoperative volume; $V_{200}$ volume at new bone level $(<200 \mathrm{HU}) ; V_{600}$ volume at mature bone level $(<600 \mathrm{HU}) ; 0$ osteogenesis index

hydrogel, and ACS. Referring to the existing literature, Geiger et al. described "enhancement of osteogenic activity of BMP with a restrictive release of BMP at an effective dose during a period coincident with the accumulation and proliferation of target cells" [25]. Li and Wozney reported that the releasing periods of rhBMP-2 were at least twice as long when treatment included the ACS compared with the control treatment without the sponge, and ACS is an appropriate carrier for BMP application [26]. In contrast, in 2008, Carter et al. mentioned that although ACS is of value for the delivery of BMP and offers good spacemaintaining ability, it should be used with caution because its overcompressed use may interfere with normal bone formation [7].

Bone density can be assessed by measuring Hounsfield units and has different values depending on the type of bone. Very dense cortical bone is expressed as $600 \mathrm{HU}$ or more, the dense cortical/spongy bone as 400 through $600 \mathrm{HU}$, and low-density bone as $200 \mathrm{HU}$ or less [8, 9]. In 2013, Tajima et al. reported that the density of periimplant, new bonelike tissue ranged from 185 to $713 \mathrm{HU}$ (mean \pm SD $=323 \pm 156.2$ ) [10].

Huh et al. found that combination therapy with bovine bone (Bio-Oss) and rhBMP-2 leads to more new bone generation than does bovine bone monotherapy and that rhBMP-2 enhanced bone regeneration [27]. In our study, the mean OI was higher in the rhBMP-2 treatment group A than in the group B, and the difference was statistically significant for new bone levels with maximum number of Hounsfield units set at 200. This result suggests that rhBMP-2 contributes significantly to new bone generation in the human body as well.

This study had the following limitations: difficulty in determining the margin when measuring postoperative lesion volume owing to the need for intraoperative osteotomy to approach the lesion; several diagnoses of the lesions; preoperative secondary infections due to the lesions; the degree of defect in the bony housing; and no consideration of the number of absorbable collagen sponges or the quantity of rhBMP-2 actually applied during the operation. Nevertheless, this study is meaningful in that we used a quantitative method to analyze the effect of rhBMP-2 in human subjects. Further studies will be needed to perform histomorphometric analyses of the effects of rhBMP-2 in the human body.

\section{Conclusions}

When rhBMP-2 was used to repair bone defects that remain after cyst enucleation, new bone formation was increased. Thus, the combination of rhBMP-2 and ACS could be considered as an alternative to conventional bone grafts. We believe that rhBMP-2 is worthy of being applied to bone defects in the oral and maxillofacial region in certain cases.

\section{Ethics approval and consent}

Human CBCT data were used in this study, but consent for patients was not necessary. This study was reviewed

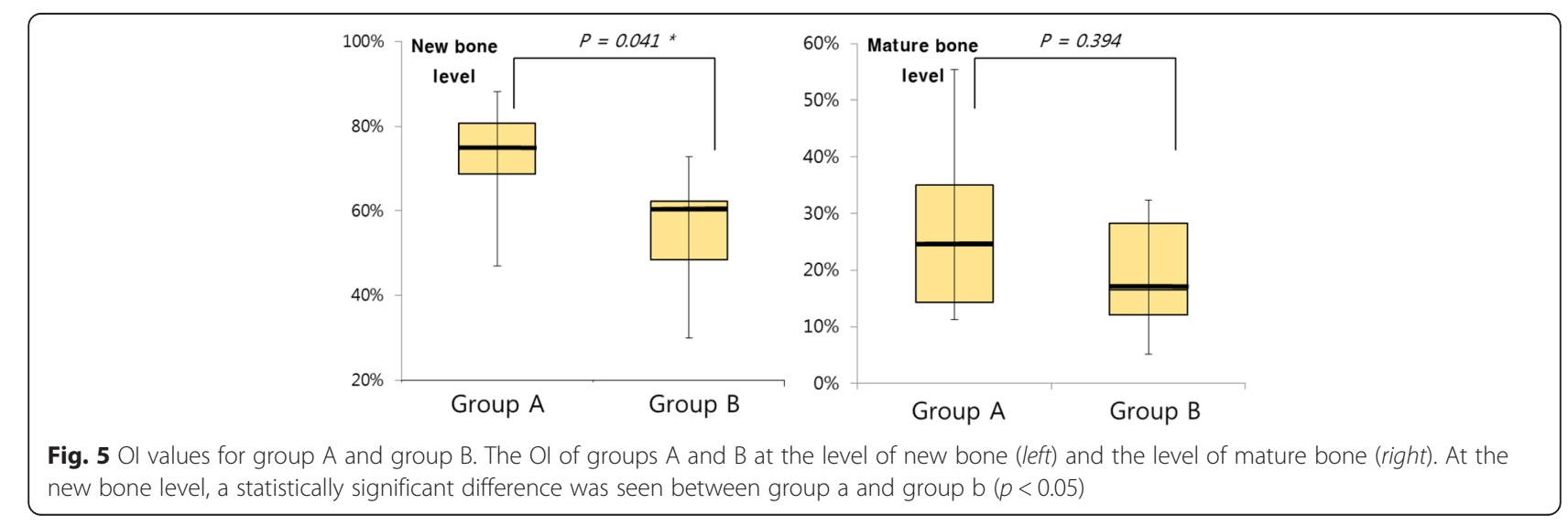


and approved by the Institutional Review Board of Ajou University Hospital (AJIRB-MED-MDB-15-203).

\section{Availability of data and materials}

The dataset supporting the conclusions of this article is included in Additional file 1.

\section{Additional file}

Additional file 1: Case form and result of data. (XLSX $13 \mathrm{~kb})$

\section{Abbreviations}

ACS: absorbable collagen sponge; Ol: osteogenesis index.

\section{Competing interests}

The authors declare that they have no competing interests.

\section{Authors' contributions}

S.I.S. carried out the surgical treatment of the patient and contributed to the conception of the report and critical revising. D.Y.H. and S.W.O. participated in the treatment, collection of data, and drafting of the manuscript. All authors read and approved the final manuscript

\section{Authors' information}

All of the authors have no affiliations with or involvement in any organization or entity with any financial interest or non-financial interest in this manuscript.

This manuscript represents original works and is not being considered for publication elsewhere.

\section{Funding}

We received no funding in support of this study.

Received: 29 March 2016 Accepted: 13 May 2016

Published online: 26 May 2016

\section{References}

1. Urist MR (1965) Bone: formation by autoinduction. Science 150(3698):893-899

2. Balaji S (2009) Mandibular cystic defect: a composite approach with rhBMP-2 and rib graft. J Maxillofac Oral Surg 8(1):27-30

3. Chenard KE, Teven CM, He T-C, Reid RR (2012) Bone morphogenetic proteins in craniofacial surgery: current techniques, clinical experiences, and the future of personalized stem cell therapy. J Biomed Biotechnol Article ID 601549,14. doi:10.1155/2012/601549.

4. Gutwald R, Haberstroh J, Stricker A, Rüther E, Otto F, Xavier SP, Oshima T, Marukawa E, Seto I, Enomoto S (2010) Influence of rhBMP-2 on bone formation and osseointegration in different implant systems after sinus-floor elevation. An in vivo study on sheep. J Craniomaxillofac Surg 38(8):571-579

5. Cicciù M, Herford AS, Juodžbalys G, Stoffella E (2012) Recombinant human bone morphogenetic protein type 2 application for a possible treatment of bisphosphonates-related osteonecrosis of the jaw. J Craniofac Surg 23(3): 784-788

6. Seok H, Lee S-K, Kim S-G, Kang T-Y, Lee M-J, Chae W-S (2014) Migration of alloplastic bone graft material in infected conditions: a case study and animal experiment. J Oral Maxillofac Surg 72(6):1093, e1091-1093. e1011

7. Carter TG, Brar PS, Tolas A, Beirne OR (2008) Off-label use of recombinant human bone morphogenetic protein-2 (rhBMP-2) for reconstruction of mandibular bone defects in humans. J Oral Maxillofac Surg 66(7):1417-1425

8. Norton MR, Gamble C (2001) Bone classification: an objective scale of bone density using the computerized tomography scan. Clin Oral Implants Res 12(1):79-84

9. Shapurian T, Damoulis PD, Reiser GM, Griffin TJ, Rand WM (2006) Quantitative evaluation of bone density using the Hounsfield index. Int J Oral Maxillofac Implants 21(2):290-297

10. Tajima N, Ohba S, Sawase T, Asahina I (2013) Evaluation of sinus floor augmentation with simultaneous implant placement using platelet-rich fibrin as sole grafting material. Int J Oral Maxillofac Implants 28(1):77-83. doi:10.11607/jomi.2613
11. Buser D, Hoffmann B, Bernard JP, Lussi A, Mettler D, Schenk RK (1998) Evaluation of filling materials in membrane-protected bone defects. A comparative histomorphometric study in the mandible of miniature pigs. Clin Oral Implants Res 9(3):137-150

12. Ogunlewe MO, Akinwande JA, Ladeinde AL, Adeyemo WL (2006) Spontaneous regeneration of whole mandible after total mandibulectomy in a sickle cell patient. J Oral Maxillofac Surg 64(6):981-984. doi:10.1016/j. joms.2006.02.008

13. Rodeo SA, Delos D, Weber A, Ju X, Cunningham ME, Fortier L, Maher S (2010) What's new in orthopaedic research. J Bone Joint Surg Am 92(14):2491-2501. doi:10.2106/JBJS.J.01174

14. Schenk RK, Buser D, Hardwick WR, Dahlin C (1994) Healing pattern of bone regeneration in membrane-protected defects: a histologic study in the canine mandible. Int J Oral Maxillofac Implants 9(1):13-29

15. Schilephake $\mathrm{H}$ (2002) Bone growth factors in maxillofacial skeletal reconstruction. Int J Oral Maxillofac Surg 31(5):469-484

16. Ettl T, Gosau M, Sader R, Reichert TE (2012) Jaw cysts-filling or no filling after enucleation? A review. J Craniomaxillofac Surg 40(6):485-493

17. Chiapasco M, Rossi A, Motta JJ, Crescentini M (2000) Spontaneous bone regeneration after enucleation of large mandibular cysts: a radiographic computed analysis of 27 consecutive cases. J Oral Maxillofac Surg 58(9):942-948

18. Hren NI, Miljavec M (2008) Spontaneous bone healing of the large bone defects in the mandible. Int J Oral Maxillofac Surg 37(12):1111-1116

19. Boyne PJ (2001) Application of bone morphogenetic proteins in the treatment of clinical oral and maxillofacial osseous defects. J Bone Joint Surgery Am 83(A Suppl 1, Pt 2):S146-S150

20. Freitas RM, Spin-Neto R, Junior EM, Pereira LAVD, Wikesjö UM, Susin C (2015) Alveolar ridge and maxillary sinus augmentation using rhBMP-2: a systematic review. Clin Implant Dent Relat Res 17(S1):e192-e201

21. Lee JB, Ryu SH, Ryu HH, Shin YC, Hwang HS (2014) Technical reports: the use of recombinant human bone morphogenic protein-2 (rhBMP-2) in treatment for cysts of the oral and maxillofacial regions. J Korean Maxillofac Plast Reconstr Surg 36(1):25-29

22. Shields LB, Raque GH, Glassman SD, Campbell M, Vitaz T, Harpring J, Shields CB (2006) Adverse effects associated with high-dose recombinant human bone morphogenetic protein-2 use in anterior cervical spine fusion. Spine 31(5):542-547

23. Takahashi Y, Yamamoto M, Tabata Y (2005) Enhanced osteoinduction by controlled release of bone morphogenetic protein-2 from biodegradable sponge composed of gelatin and $\beta$-tricalcium phosphate. Biomaterials 26(23):4856-4865

24. Kim M-J, Kim K-M, Kim J, Kim K-N (2014) BMP-2 promotes oral squamous carcinoma cell invasion by inducing CCL5 release. PLoS One 9(10), e108170. doi:10.1371/journal.pone.0108170

25. Geiger M, Li R, Friess W (2003) Collagen sponges for bone regeneration with rhBMP-2. Adv Drug Deliv Rev 55(12):1613-1629

26. Li RH, Wozney JM (2001) Delivering on the promise of bone morphogenetic proteins. Trends Biotechnol 19(7):255-265

27. Huh JB, Yang JJ, Choi KH, Bae JH, Lee JY, Kim SE, Shin SW (2015) Effect of rhBMP-2 immobilized anorganic bovine bone matrix on bone regeneration. Int J Mol Sci 16(7):16034-16052. doi:10.3390/ijms160716034

\section{Submit your manuscript to a SpringerOpen ${ }^{\circ}$ journal and benefit from:}

- Convenient online submission

- Rigorous peer review

- Immediate publication on acceptance

- Open access: articles freely available online

- High visibility within the field

- Retaining the copyright to your article

Submit your next manuscript at $>$ springeropen.com 